\title{
Kajian Daya Dukung Jalan dan Prioritas Penanganannya di Perbatasan Kota Depok dengan Kota Administrasi Jakarta Selatan
}

\author{
Study of Roads Carrying Capacity and Handling Priority at the Border \\ of Depok City and South Jakarta
}

\section{Corry Nurmala ${ }^{1}$, Baba Barus $^{2}$ and Umar Mansyur ${ }^{3}$}

\begin{abstract}
Abstrak: Daya dukung jalan dapat diartikan sebagai kapasitas jalan untuk mendukung kendaraan yang melintas. Penelitian ini bertujuan untuk memberikan arahan prioritas penanganan jalan di perbatasan Kota Depok dengan Kota Administrasi Jakarta Selatan dengan melihat kondisi fisik, perlengkapan jalan dan fasilitas pendukung, tingkat kepuasan masyarakat dan daya dukung jalan. Menggunakan metode analisis deskriptif dari hasil survei lapang untuk kondisi fisik jalan dan perlengkapan jalan, metode CSI untuk hasil kuesioner serta LoS untuk daya dukung jalan. Hasil penelitian menunjukkan bahwa kondisi jalan dalam kategori sedang dan rusak ringan, kondisi perlengkapan jalan dan fasilitas pendukung di Jakarta Selatan lebih baik daripada di Kota Depok dan tingkat kepuasan masyarakat terhadap jalan dalam kategori kurang puas dan cukup puas. Daya dukung jalan di perbatasan berada dalam kategori cukup baik hingga sangat buruk. Berdasarkan hasil analisis yang telah dilakukan sebelumnya, maka ditentukanlah prioritas penanganan jalan, untuk jalan di Kota Depok yaitu prioritas 1 pada Jalan Raya Margonda, prioritas 2 untuk Jalan Tanah Baru, prioritas 3 Kukusan Raya dan untuk jalan di Jakarta Selatan yaitu prioritas 1 untuk Jalan Lenteng Agung Raya, prioritas 2 untuk Jalan Srengseng Sawah, prioritas 3 untuk Jalan Moh. Kahfi I dan Moh. Kahfi II.
\end{abstract}

\section{Kata kunci: Daya Dukung, Jalan, Perbatasan Wilayah, Prioritas Penanganan}

\begin{abstract}
Roads carrying capacity can be interpreted as a road capacity to support passing vehicles. This study was aimed to determine the priority of road handling at border of Depok City with South Jakarta by looking at the physical condition, road equipment and supporting facilities, costumer satisfaction and roads carrying capacity. Using descriptive analysis method for the physical conditions of roads and road equipment, CSI methods for the results of questionnaires and LoS for roads carrying capacity. The results showed that the road conditions in the category of moderate and lightly damaged conditions, conditions of road equipment and supporting facilities in South Jakarta were better than those on roads in Depok City and roads costumer satisfaction index in the category was less satisfied and quite satisfied. Roads carrying capacity at the border is in the fairly good to very bad category. The priority of road handling is determined, for roads at Depok City are first priority for Margonda Road, second priority for Tanah Baru Road, third priority Kukusan Raya Road and for roads at South Jakarta are first priority for Lenteng Agung Raya Road, second priority for Srengseng Sawah Road, third priority for Moh. Kahfi I Road and Moh. Kahfi II Road.
\end{abstract}

Keywords: Border Area, Carrying Capacity, Handling Priority, Road

\footnotetext{
${ }^{1}$ Program Studi Perencanaan Wilayah, Sekolah Pasca Sarjana Institut Pertanian Bogor

${ }^{2}$ Departemen Ilmu Tanah dan Sumberdaya Lahan, Fakultas Pertanian Institut Pertanian Bogor

${ }^{3}$ Program Studi Perencanaan Wilayah, Sekolah Pasca Sarjana Institut Pertanian Bogor
} 


\section{PENDAHULUAN}

Jalan raya merupakan prasarana transportasi darat untuk melayani pergerakan manusia dan atau barang dari suatu tempat ke tempat lain secara aman, nyaman dan ekonomis (Hadijah dan Putra, 2017), tujuan dibangunnya jalan yaitu untuk meningkatkan aksesibilitas dan mobilitas kegiatan sosial ekonomi dalam masyarakat. Jalan merupakan salah satu bagian dari pelayanan publik yang tak terpisahkan dari kewajiban negara untuk mensejahterakan rakyatnya (Aziza, 2016) dan sudah menjadi tugas pemerintah daerah menyusun kebijakan publik sesuai dengan kehendak publik sehingga penyelenggaraan pelayanan publik yang berkualitas dapat tercapai tak terkecuali di daerah perbatasan.

Kota Depok sebagai daerah penyangga dan pendukung aktifitas perekonomian yang berbatasan langsung dengan Ibu Kota Negara menjadikannya sebagai daerah yang sangat strategis untuk permukiman yang kemudian berdampak kepada tingginya arus migrasi yang masuk ke Kota Depok. Begitu pula dengan kecamatan di Kota Administrasi Jakarta Selatan yang berbatasan dengan Kota Depok, daya tarik kecamatan tersebut cenderung tinggi dibanding daerah lain di DKI Jakarta karena masih melimpahnya ketersediaan air bersih, menyebabkan pengembang datang membangun perumahan di daerah tersebut. Sebanyak 87,7\% penduduk Kota Depok bekerja di DKI Jakarta (Sitanala, 2005) dan 69,46\% penglaju tersebut menggunakan kendaraan pribadi (Kentjana et al., 2016). Besarnya jumlah penglaju tersebut membutuhkan kualitas jalan yang baik.

Menurut Undang-Undang Nomor 32 Tahun 2009 Tentang Perlindungan Dan Pengelolaan Lingkungan Hidup, daya dukung lingkungan hidup adalah kemampuan lingkungan hidup untuk mendukung perikehidupan manusia, mahluk lain dan keseimbangan antar keduanya, dalam hal aspek jalan maka daya dukung jalan dapat diartikan sebagai kapasitas/kemampuan jalan untuk mendukung kendaraan yang melintas. Daya dukung jalan yang sudah terlampaui dan tidak mendapatkan penanganan dari pemerintah daerah akan berdampak pada terhambatnya pergerakan barang/jasa.

Berdasarkan hal tersebut, maka diperlukan perencanaan prioritas penanganan jalan khususnya di perbatasan Kota Depok dengan Kota Administrasi Jakarta Selatan dengan harapan penanganan yang dilakukan dapat lebih efektif dan efisien. Penelitian ini bertujuan untuk memberikan arahan prioritas penanganan jalan di perbatasan Kota Depok dengan Kota Administrasi Jakarta Selatan dengan melihat kondisi fisik, perlengkapan jalan dan fasilitas pendukung, tingkat kepuasan masyarakat dan daya dukung jalan.

\section{METODE}

\section{Lokasi dan Waktu Penelitian}

Penelitian dilakukan di daerah perbatasan Kota Depok dengan Kota Administrasi Jakarta Selatan dengan cakupan wilayah yaitu Kecamatan Beji Kota Depok dengan Kecamatan Jagakarsa Kota Administrasi Jakarta Selatan, terdiri dari 3 kelurahan di Kecamatan Beji (Kelurahan Tanahbaru, Kelurahan Kukusan dan Kelurahan Pondok Cina) dan 2 kelurahan di Kecamatan Jagakarsa (Kelurahan Cipedak dan Kelurahan Srengsengsawah) dengan luas total lokasi penelitian 2.065 ha. Waktu penelitian dilakukan selama lima bulan yaitu sejak bulan Mei hingga Oktober 2018.

\section{Alat Penelitian}

Peralatan yang digunakan terdiri dari kuesioner penelitian, Global Positioning System (GPS), kamera dijital, hand counter, alat tulis, software ArcGIS 10.1 dan Microsoft Office. 


\section{Jenis dan Sumber Data Penelitian}

Data yang digunakan terdiri atas data primer (data volume kendaraan, data kondisi jalan, data geometrik jalan, data perlengkapan jalan dan fasilitas pendukung, data lingkungan jalan) dan data sekunder (Peta RBI, data jalan, RTRW Kota Depok Tahun 20122032 dan RTRW DKI Jakarta Tahun 2010-2030).

\section{Customer Satisfaction Index (CSI)}

Data hasil kuesioner di analisis menggunakan metode CSI. Besarnya CSI diperoleh dari hasil langkah-langkah perhitungan sebagai berikut (Dickson dalam Pratama et al., 2011): (1) menentukan Mean Importance Score (MIS) dan Mean Satisfaction Score (MSS) tiap atribut; (2) menentukan Weight Factor (WF), nilai dari MIS masing-masing atribut yang dinyatakan dalam bentuk persen terhadap total MIS untuk seluruh atribut yang diuji; (3) menentukan Weighting Score (WS), fungsi dari MSS dikali dengan WF; (4) menentukan CSI, dengan rumus:

$$
C S I=\frac{\sum_{i=1}^{n} W S_{i}}{5} x 100 \%
$$

dimana CSI $=$ Customer Satifaction Index dan WS $=$ Weighting Score yang diperoleh dari perhitungan sebelumnya. Nilai CSI kemudian dipadupadankan dengan kategori tingkat kepuasan masyarakat mengacu pada tabel tingkat kepuasan masyarakat Phebruanti dalam Pratama et. al (2011) (Tabel 1).

Tabel 1. Tingkat Kepuasan Masyarakat

\begin{tabular}{ccc}
\hline No & Nilai CSI & Kategori \\
\hline 1 & $81 \%-100 \%$ & Sangat Puas \\
2 & $66 \%-80,99 \%$ & Puas \\
3 & $51 \%-65,99 \%$ & Cukup Puas \\
4 & $35 \%-50,99 \%$ & Kurang Puas \\
5 & $0 \%-34,99 \%$ & Tidak Puas \\
\hline
\end{tabular}

Sumber: Phebruanti dalam Pratama et al., 2011

\section{Analisis Level of Service (LoS)}

Analisis yang digunakan untuk mengetahui daya dukung jalan didasarkan pada LoS. LoS diukur berdasarkan rasio arus/volume lalulintas dengan kapasitas jalan. Arus lalulintas yaitu jumlah kendaraan bermotor yang melalui titik pada jalan per satuan waktu (DEPPU 1997) Adapun rumus perhitungannya sebagai berikut (DEPPU 1997):

$$
\begin{gathered}
\mathrm{C}=\mathrm{Co} . \mathrm{Fw} \cdot \mathrm{Fsp} . \mathrm{Fsf} . \mathrm{Fcs} \\
D S=\frac{V}{C}
\end{gathered}
$$

keterangan:

$\mathrm{C}=$ kapasitas (smp/jam); Co = kapasitas dasar (smp/jam); $\mathrm{Fw}=$ faktor kesesuaian lebar jalur lalulintas; Fsp = faktor kesesuaian pemisahan arah/perjalanan (jalan dua arah); Fsf = faktor kesesuaian jalur pergerakan/hambatan samping; $\mathrm{Fcs}=$ faktor kesesuaian ukuran kota; V = volume lalu lintas (smp/jam); DS = derajat kejenuhan (DS).

Nilai V/C ratio kemudian ditentukan daya dukungnya berdasarkan Tabel 2. 
Tabel 2. Status Daya Dukung Jalan

\begin{tabular}{clc}
\hline Derajat Kejenuhan & \multicolumn{1}{c}{ Kondisi Arus } & Daya Dukung \\
\hline $0-0,20$ & $\begin{array}{l}\text { Kondisi arus bebas dengan kecepatan } \\
\text { tinggi tanpa hambatan } \\
\text { Arus stabil tapi kecepatan operasi mulai } \\
\text { dibatasi oleh kondisi lalu lintas }\end{array}$ & Sangat aman \\
Arus stabil, tetapi kecepatan dan gerak & Aman \\
& kendaraan dikendalikan \\
& Arus mendekati tidak stabil, kecepatan \\
& masih dikendalikan 0,74 & Cukup Aman \\
$0,75-0,84$ & $\begin{array}{l}\text { Volume lalu lintas mendekati pada } \\
\text { kapasitas arus tidak stabil, kecepatan } \\
\text { terkadang terhenti } \\
\text { Arus yang dipaksakan atau macet, } \\
\text { kecepatan rendah, volume dibawah } \\
\text { kapasitas, antrian panjang dan terjadi } \\
\text { hambatan yang besar. }\end{array}$ & Tidak Ampir Terlampaui \\
& & Telah Terlampaui \\
&
\end{tabular}

Sumber: Modifikasi Morlok, 1991 dalam Palin et al., 2013

\section{Sintesis Logika Penetapan Prioritas Penanganan Jalan}

Kattsoff (1989) dalam Miri (2014) mendefinisikan sintesis logika adalah kegiatan berpikir logis yang melakukan penggabungan semua pengetahuan yang diperoleh untuk menyusun suatu pandangan atau konsep. Pengambilan keputusan berdasarkan pertimbangan dari hasil analisis yang telah dilakukan sebelumnya dengan menggunakan pendekatan penilaian parameter pada 6 indikator yaitu kondisi jalan, kondisi perlengkapan jalan dan fasilitas pendukung, tingkat kepuasan, daya dukung, keterkaitan dengan struktur ruang, keterkaitan dengan pola ruang dan penanganan jalan dalam RTRW. Contoh nilai parameter per indikator disajikan pada Tabel 3.

Tabel 3. Contoh Parameter Penilaian Penanganan Jalan

\begin{tabular}{llc}
\hline \multicolumn{1}{c}{ Indikator } & \multicolumn{1}{c}{ Parameter Prioritas } & Nilai Parameter \\
\hline Kondisi jalan & Baik & 1 \\
(Irawan et al., 2016) & Sedang & 2 \\
& Rusak ringan & 3 \\
& Rusak berat & 4 \\
Keterkaitan dengan & Tidak menghubungkan langsung dengan & 1 \\
struktur ruang & pusat pemeritahan/pusat kegiatan \\
(Kartikasari, 2017) & $\begin{array}{l}\text { Menghubungkan langsung dengan pusat } \\
\text { pemerintahan/pusat kegiatan }\end{array}$ & 2 \\
\hline
\end{tabular}

\section{HASIL DAN PEMBAHASAN}

Hasil survei penentuan ruas jalan utama terhadap masyarakat yang tinggal di perbatasan Kota Depok dan Kota Administrasi Jakarta Selatan menunjukkan terdapat 7 ruas jalan utama yang menjadi pilihan terbanyak masyarakat saat melaju yaitu: Jalan Raya Margonda, Jalan Raya Lenteng Agung Raya, Jalan Kukusan Raya, Jalan Srengseng Sawah, Jalan Tanah Baru, Jalan Moh. Kahfi I dan Jalan Moh. Kahfi II.

\section{Kondisi Jalan}

Kondisi jalan didasarkan pada kerataan permukaan jalan (Siahaan dan Surbakti, 2014). Hasil analisis berdasarkan data survei primer pada tujuh ruas jalan menunjukkan 4 jalan masuk dalam kondisi sedang dan 3 jalan masuk dalam kondisi rusak ringan (Gambar 1). 


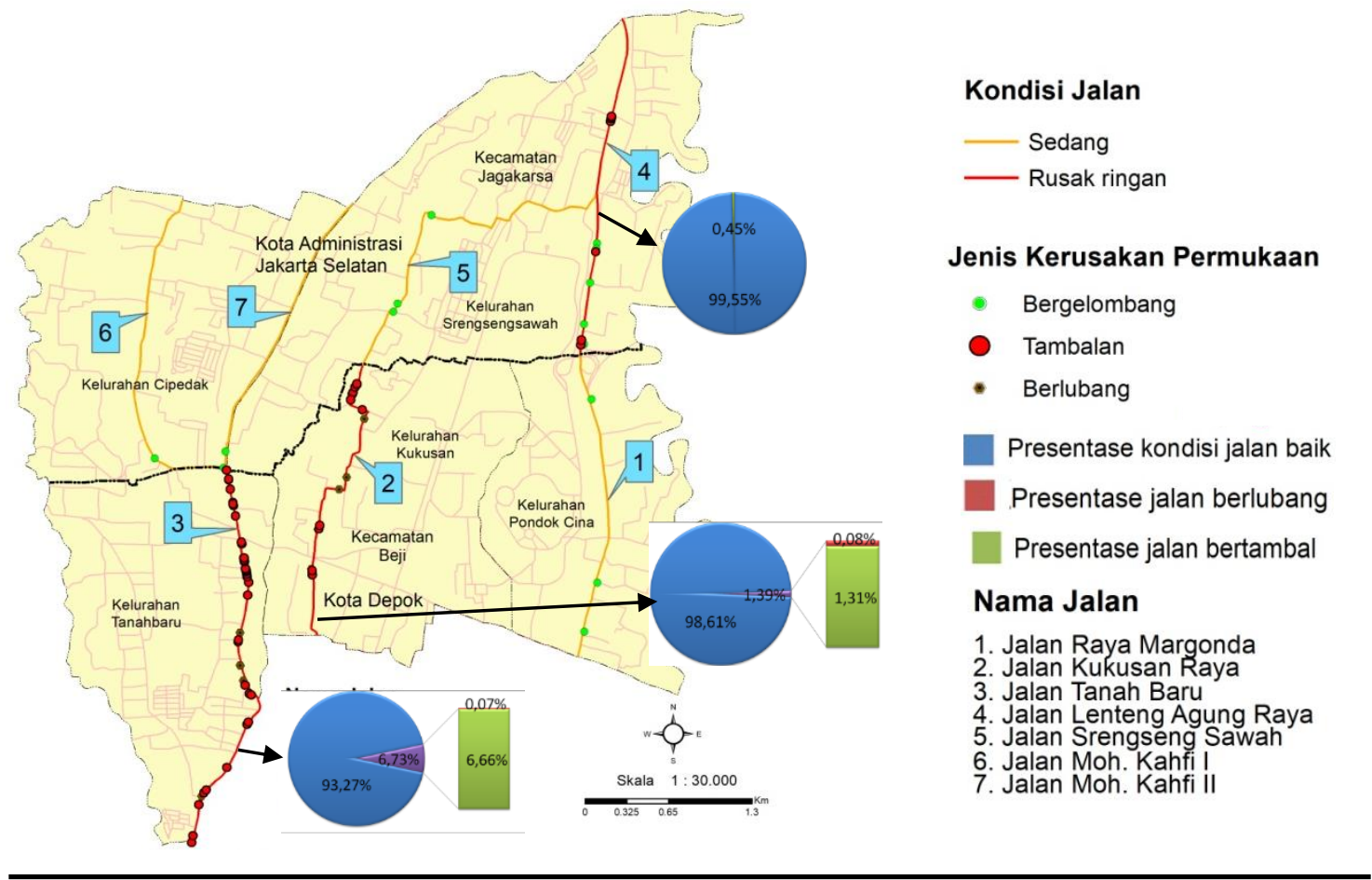

\section{Gambar 1. Kondisi Jalan Lokasi Penelitian}

Kondisi jalan di Kota Administrasi Jakarta Selatan, tiga jalan dalam kondisi sedang (Jalan Srengseng Sawah, Jalan Moh. Kahfi I dan Jalan Moh. Kahfi II) dan satu jalan dalam kondisi rusak ringan (Jalan Lenteng Agung Raya), sedangkan untuk jalan di Kota Depok, dua jalan dalam kondisi rusak ringan (Jalan Kukusan Raya dan Jalan Tanah Baru) dan satu jalan dalam kondisi sedang (Jalan Raya Margonda). Kondisi jalan yang rusak berpengaruh terhadap pergerakan atau mobilitas kendaraan, barang maupun jasa, tidak hanya dapat menghambat dari sisi waktu akan tetapi dapat pula membahayakan keselamatan para pengguna jalan terutama bagi pemakai sepeda dan sepeda motor.

\section{Kondisi Perlengkapan Jalan dan Fasilitas Pendukung}

Perlengkapan jalan dan fasilitas pendukung yang dapat dijumpai di lokasi penelitian sebanyak 17 jenis yang tersebar pada 7 ruas jalan yang dikaji (Tabel 4).

Tabel 4. Ketersediaan Perlengkapan Jalan dan Fasilitas Pendukung per Ruas Jalan

\begin{tabular}{|c|c|c|c|c|c|c|c|c|c|c|c|c|c|c|c|c|c|c|}
\hline \multirow{2}{*}{ Nama Jalan } & \multicolumn{18}{|c|}{ Jenis Perlengkapan Jalan dan Fasilitas Pendukunga b } \\
\hline & 1 & 2 & 3 & 4 & 5 & 6 & 7 & 8 & 9 & 10 & 11 & 12 & 13 & 14 & 15 & 16 & 17 & Total \\
\hline 1. Raya Margonda & $\mathrm{v}$ & $\mathrm{v}$ & $\mathrm{v}$ & - & $\mathrm{v}$ & $\mathrm{v}$ & - & - & $\mathrm{v}$ & $\mathrm{V}$ & $\mathrm{V}$ & $\mathrm{V}$ & $\mathrm{v}$ & $\mathrm{v}$ & $\mathrm{V}$ & $\mathrm{v}$ & - & 13 \\
\hline 2. Kukusan Raya & $\mathrm{v}$ & $\mathrm{v}$ & - & - & - & $\mathrm{v}$ & $\mathrm{v}$ & - & $\mathrm{v}$ & - & - & - & - & $\mathrm{v}$ & - & - & - & 6 \\
\hline 3.Tanah Baru & $\mathrm{v}$ & $\mathrm{v}$ & - & - & - & $\mathrm{v}$ & $\mathrm{v}$ & $\mathrm{v}$ & $\mathrm{v}$ & - & - & - & $\mathrm{v}$ & - & - & $\mathrm{v}$ & - & 8 \\
\hline 4.Lenteng Agung Raya & $\mathrm{v}$ & $\mathrm{v}$ & $\mathrm{v}$ & - & - & $\mathrm{v}$ & - & $\mathrm{v}$ & $\mathrm{v}$ & - & - & - & $\mathrm{v}$ & $\mathrm{v}$ & $\mathrm{v}$ & $\mathrm{v}$ & $\mathrm{v}$ & 11 \\
\hline 5. Srengseng Sawah & $\mathrm{v}$ & $\mathrm{v}$ & - & $\mathrm{v}$ & - & $\mathrm{v}$ & $\mathrm{v}$ & $\mathrm{v}$ & - & - & - & - & - & $\mathrm{v}$ & - & - & - & 7 \\
\hline 6. Moh. Kahfi I & $\mathrm{v}$ & $\mathrm{v}$ & $\mathrm{v}$ & - & - & - & $\mathrm{v}$ & - & $\mathrm{v}$ & - & - & - & - & $\mathrm{v}$ & - & $\mathrm{v}$ & - & 7 \\
\hline 7. Moh. Kahfi II & $\mathrm{v}$ & $\mathrm{v}$ & $\mathrm{V}$ & - & - & $\mathrm{v}$ & - & - & - & - & - & - & $\mathrm{v}$ & - & - & $\mathrm{V}$ & - & 6 \\
\hline
\end{tabular}

Sumber: survei primer (2018)

Keterangan: 1. rambu lalulintas; 2. lampu jalan; 3. marka jalan; 4. alat pembatas kecepatan; 5. alat pembatas tinggi dan lebar kendaraan; 6. pagar pengaman; 7. cermin tikungan; 8. tanda patok tikungan; 9. pita penggaduh; 10. jalur khusus angkutan umum; 11. jalur sepeda motor; 12. jalur sepeda; 13. trotoar; 14. zebra cross; 15 . JPO; 16. halte; 17 . fasilitas perpindahan moda. ${ }^{\mathrm{b}} \mathrm{v}=$ ada; - = tidak ada. 
Persentase kondisi dari masing-masing jenis perlengkapan jalan dan fasilitas pendukung per ruas jalan disajikan pada Tabel 5 dan Gambar 2. Hasil analisis menunjukkan bahwa kondisi perlengkapan jalan dan fasilitas pendukung di Kota Administrasi Jakarta Selatan (96\%) lebih baik dibandingkan dengan ruas jalan di Kota Depok (86\%), persentase yang dapat dikatakan baik namun belum mencapai $100 \%$ karena masih dijumpai kerusakan. Dari hasil tersebut menggambarkan bahwa perhatian pemerintah daerah setempat cukup baik terhadap keberadaan dari perlengkapan jalan dan fasilitas pendukung, sebagaimana yang dikatakan Muanisah dan Ernawati (2014) bahwa perlengkapan jalan dan fasilitas pendukung merupakan unsur yang penting dalam penyelenggaraan lalu lintas dan angkutan jalan dalam rangka memberikan perlindungan keselamatan, keamanan, ketertiban, dan kelancaran lalu lintas dan angkutan jalan serta sebagai bentuk penegakkan peraturan bagi pengguna jalan (Chengula 2018).

Tabel 5. Kondisi Perlengkapan Jalan dan Fasilitas Pendukung

\begin{tabular}{|c|c|c|c|c|c|c|c|}
\hline \multirow{2}{*}{ No } & \multirow{2}{*}{ Nama Jalan } & \multicolumn{2}{|c|}{$\begin{array}{c}\text { Perlengkapan jalan dan } \\
\text { fasilitas pendukunga }\end{array}$} & \multicolumn{2}{|c|}{$\begin{array}{l}\text { Perlengkapan jalan dan } \\
\text { fasilitas pendukung }\end{array}$} & \multirow{2}{*}{$\begin{array}{c}\text { Rata-rata } \\
\text { kondisi } \\
\text { baik } \\
(\%)\end{array}$} & \multirow{2}{*}{ Kategori } \\
\hline & & Total (titik) & $\begin{array}{l}\text { Kondisi } \\
\text { baik (\%) }\end{array}$ & $\begin{array}{l}\text { Total panjang } \\
\text { (m) }\end{array}$ & $\begin{array}{l}\text { Kondisi } \\
\text { baik (\%) }\end{array}$ & & \\
\hline 1 & Raya Margonda & 126 & 84 & 4.597 & 88 & 86 & Rendah \\
\hline 2 & Kukusan Raya & 45 & 64 & 45 & 100 & 82 & Rendah \\
\hline 3 & Tanah Baru & 88 & 83 & 1.880 & 99 & 91 & Sedang \\
\hline 4 & $\begin{array}{l}\text { Lenteng Agung } \\
\text { Raya }\end{array}$ & 355 & 96 & 7.147 & 90 & 93 & Sedang \\
\hline 5 & $\begin{array}{l}\text { Srengseng } \\
\text { Sawah }\end{array}$ & 117 & 96 & 131 & 100 & 98 & Tinggi \\
\hline 6 & Moh. Kahfi I & 104 & 96 & 2.711 & 99 & 98 & Tinggi \\
\hline 7 & Moh. Kahfi II & 94 & 91 & 3.745 & 97 & 94 & Tinggi \\
\hline
\end{tabular}

Sumber: Hasil analisis (2018)

${ }^{a}$ Perlengkapan jalan dan fasilitas pendukung berbentuk titik (rambu lalulintas; lampu jalan; cermin tikungan; tanda patok tikungan; pita penggaduh; alat pembatas kecepatan; zebra cross; JPO; halte; fasilitas perpindahan moda); ${ }^{b}$ perlengkapan jalan dan fasilitas pendukung berbentuk garis (pagar pengaman; marka jalan; trotoar; alat pembatas tinggi dan lebar kendaraan)

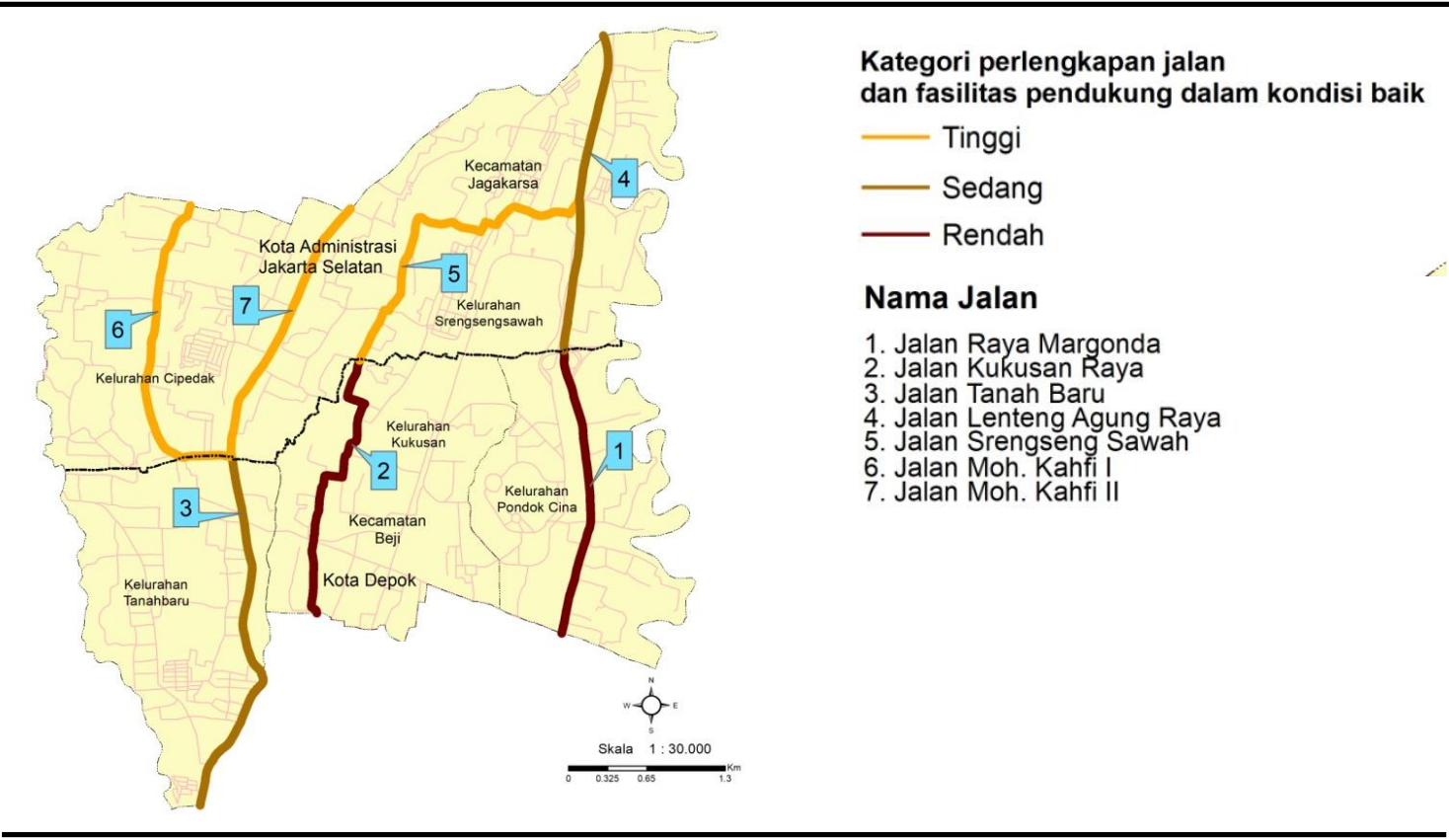

Gambar 2. Kondisi Perlengkapan Jalan dan Fasilitas Pendukung 


\section{c. Kondisi Jalan Berdasarkan Tingkat Kepuasan Masyarakat}

Hasil olah data dan analisis dari penyebaran kuesioner kepada responden diperoleh informasi tingkat kepuasan masyarakat terhadap masing-masing ruas jalan yang dikaji berdasarkan atas tiga kriteria penilaian seperti yang disajikan pada Gambar 3.

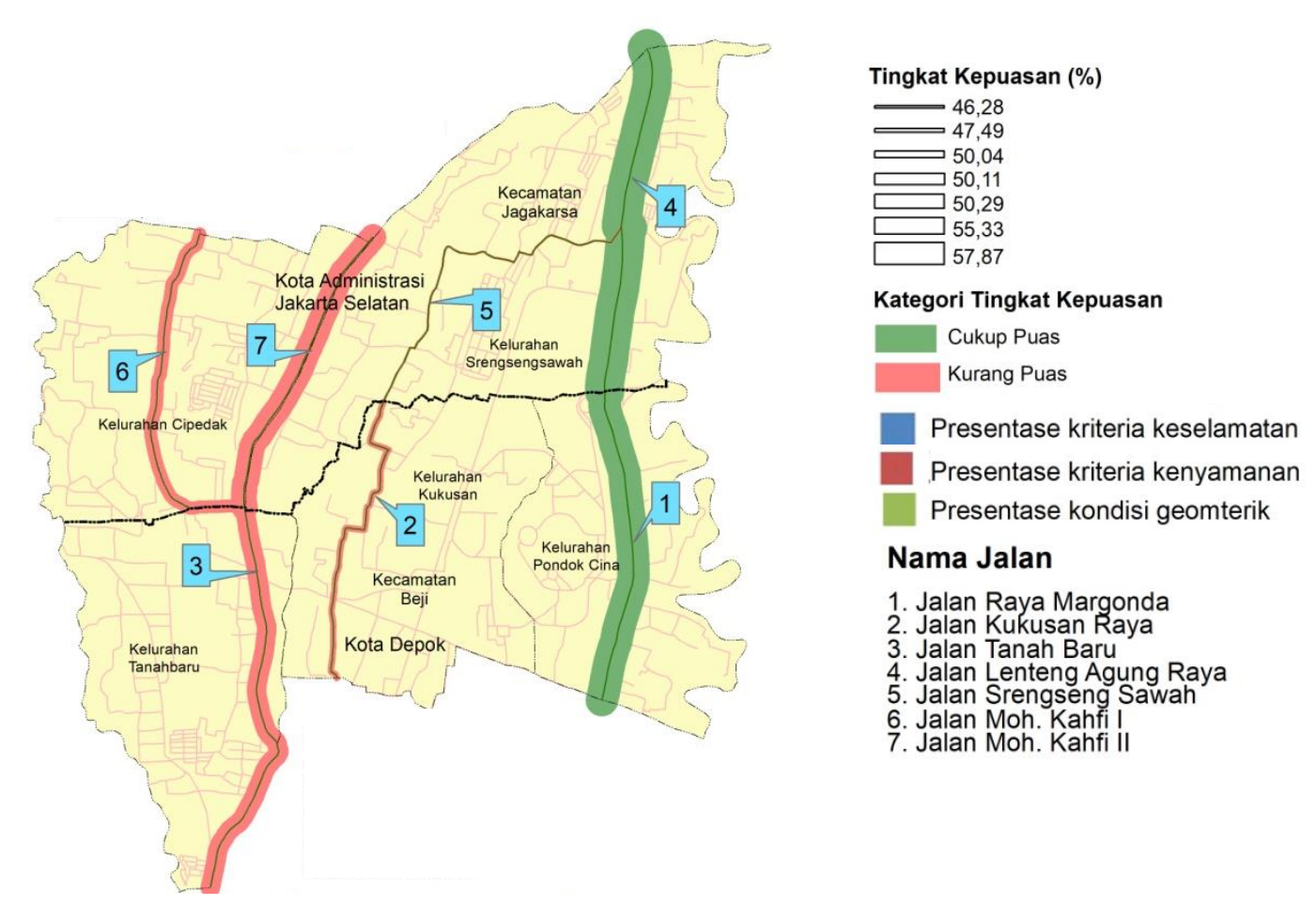

Gambar 3. Tingkat Kepuasan Masyarakat Terhadap Kondisi Jalan

Pada tujuh ruas jalan di lokasi penelitian, tingkat kepuasan masyarakat terhadap kondisi jalan di perbatasan memiliki nilai 52,10\% untuk Kota Depok dan 54,52\% untuk Kota Administrasi Jakarta Selatan. Nilai tersebut berada pada rentang interval $51 \%$ $65,99 \%$, dengan arti cukup puas. Meskipun demikian, nilai capaian tingkat kepuasan masyarakat masih jauh dari angka 100\% (sangat puas), hal ini menandakan bahwa masingmasing pemerintah kota baik Kota Depok maupun Kota Administrasi Jakarta Selatan masih memiliki tanggung jawab guna meningkatkan pelayanan dalam hal penyediaan infrastruktur yang baik dan berkualitas bagi masyarakat sebagai pengguna manfaat.

\section{Daya Dukung Jalan}

Perhitungan kapasitas jalan pada masing-masing ruas jalan didasarkan pada karakteristik lingkungan jalannya sesuai dengan yang diatur dalam Manual Kapasitas Jalan Indonesia Tahun 1997 oleh Direktorat Bina Marga Kementerian Pekerjaan Umum Republik Indonesia. Karaktersitik lingkungan jalan diperoleh dari hasil survei primer dan acuan dari data sekunder dinas terkait yaitu dinas bina marga dari masing-masing pemerintah daerah.

Berdasarkan hasil perhitungan kapasitas jalan dan data empiris hasil survei, maka dapat diketahui daya dukung pada masing-masing ruas jalan dengan melihat hasil dari rasio volume lalu lintas dibagi dengan kapasitas jalan. Perbandingan antara volume lalu lintas dengan kapasitas jalan disajikan pada Gambar 4 dan daya dukung pada Gambar 5. 


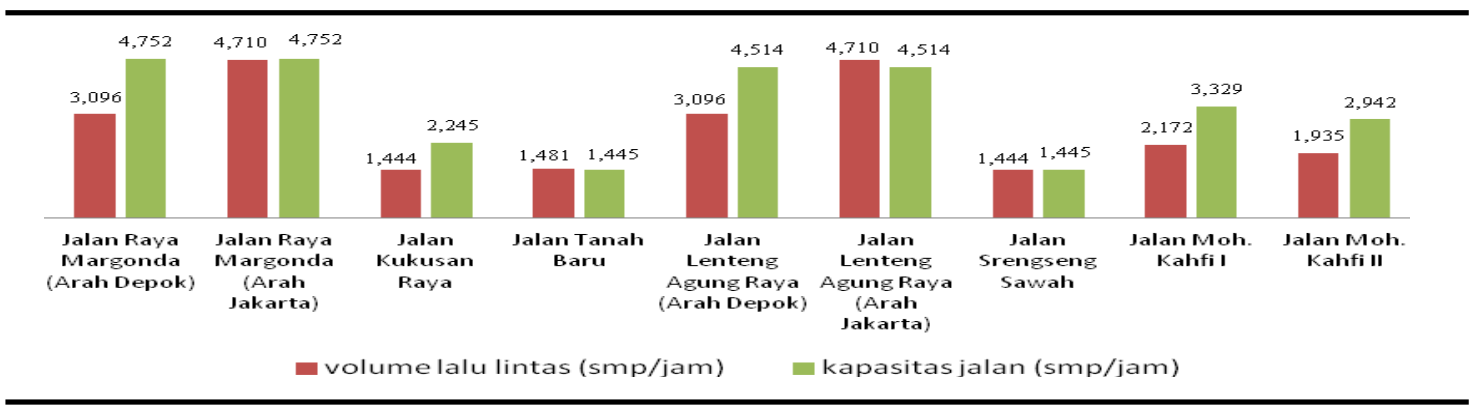

Gambar 4. Perbandingan Volume Lalu Lintas dengan Kapasitas Jalan

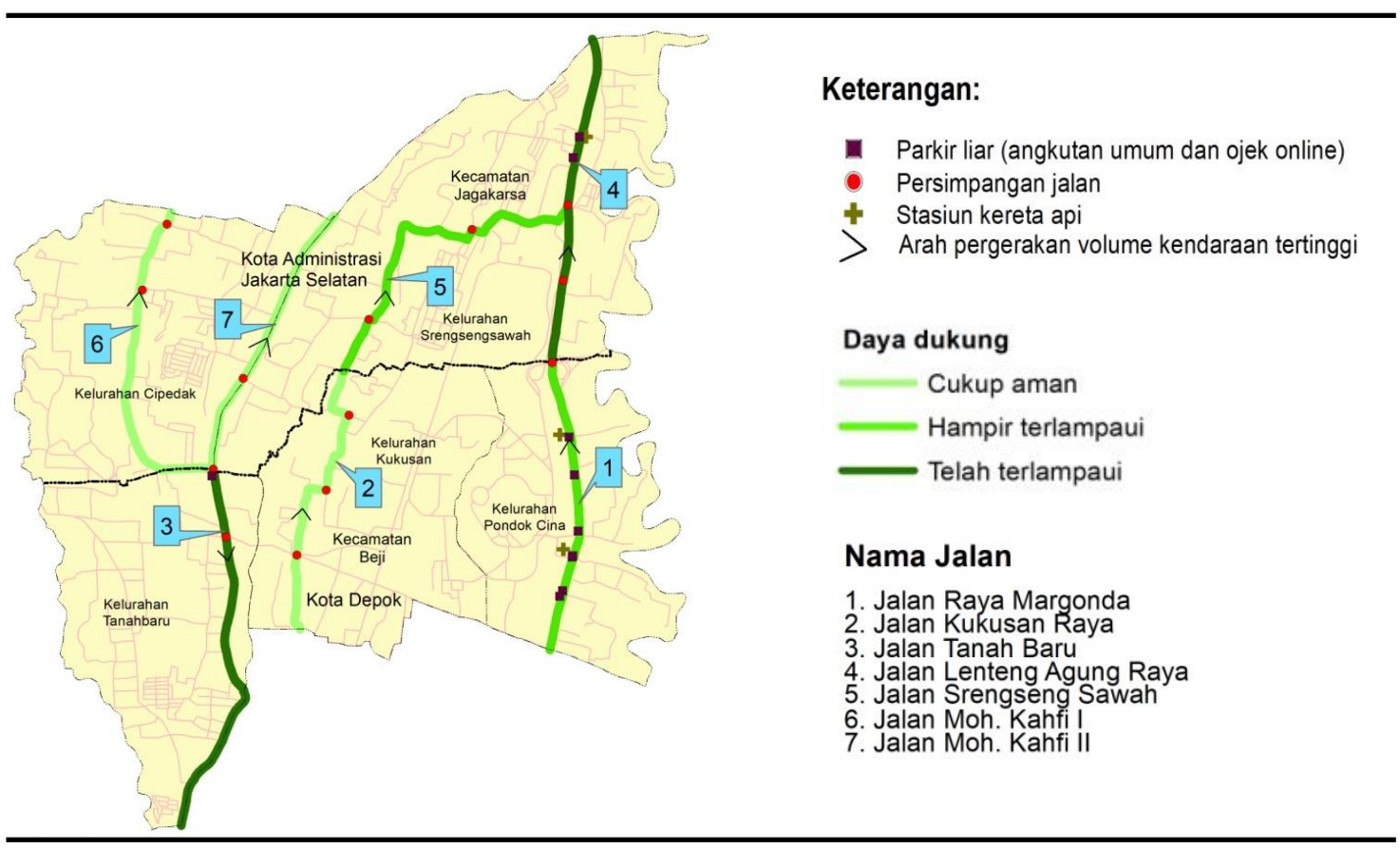

Gambar 5. Daya Dukung Jalan

Hasil analisis menunjukkan bahwa kondisi daya dukung jalan mulai dari kategori cukup baik hingga sangat buruk. Dari Gambar 5 terlihat bahwa keberadaan titik-titik persimpangan jalan, parkir liar (angkutan umum dan ojek online) serta keberadaan stasiun kereta api memberikan sumbangsih terhadap penurunan daya dukung jalan yang berdampak pada kemacetan, pada ruas Jalan Raya Margonda dan Jalan Lenteng Agung Raya ketiga faktor tersebut sangat berpengaruh terhadap tingkat pelayanan dan daya dukungnya. Hal ini sejalan dengan penelitian Kentjana (2016) dan Mathew (2017) yang menyatakan bahwa tingkat kemacetan arus lalu lintas semakin tinggi pada jalur-jalur yang menuju pusat pelayanan transportasi dan persimpangan yang menyebabkan terjadinya interupsi lalulintas, dengan puncaknya pada perpotongan jalur jalan dengan rel kereta api.

Untuk ruas Jalan Tanah Baru, daya dukung jalan sangat buruk atau terlampaui lebih disebabkan pada kondisi volume kendaraan yang melebihi kapasitas jalan dan adanya percabangan jalan di perbatasan Kota Depok dengan Kota Administrasi Jakarta Selatan, dimana lebar jalan yang sempit menjadi faktor utamanya sehingga terjadi perubahan dalam kecepatan akibat pembatasan lalulintas (Mathew, 2007). Dari hasil analisis menunjukkan pula bahwa 6 ruas jalan dari 7 ruas jalan yang di kaji atau sebesar $85,7 \%$ arah pergerakan 
penyumbang volume kendaraan tertinggi yaitu dari Kota Depok menuju DKI Jakarta.Ruas jalan di Kota Administrasi Jakarta Selatan memiliki daya dukung yang lebih baik dibandingkan dengan ruas jalan di Kota Depok. Hasil daya dukung menggambarkan bahwa masing-masing pemerintah harus segera memutuskan alternatif penyelesaian dari kondisi lalu lintas yang ada. Informasi yang diperoleh dari Dinas Perhubungan Kota Depok bahwa pertumbuhan jalan di Kota Depok hanya sekitar 0,7\% sedangkan pertumbuhan jumlah kendaraan bermotor hampir mencapai angka 9\% dan angka pertumbuhan penduduk $3,53 \%$. Jumlah penduduk yang terus meningkat akan berpengaruh pada peningkatan jumlah kendaraan yang melintas di jalan raya, maka tidak menutup kemungkinan kondisi lalu lintas hasil dari penelitian ini akan mengalami penurunan daya dukungnya di masa mendatang.

\section{Lokasi Penelitian dalam Rencana Tata Ruang Wilayah}

\section{Kota Depok}

Kecamatan Beji yang menjadi lokasi penelitian termasuk ke dalam wilayah pelayanan PPK. Di lihat dari pola ruang yang ada, ketiga kelurahan yang diteliti terbagi atas tiga kawasan yaitu kawasan perumahan kepadatan sedang, kawasan fasilitas pelayanan umum fasilitas pendidikan dan kawasan lindung. Jika dirinci per ruas jalan, maka dapat diketahui bahwa ruas Jalan Raya Margonda berada pada Kawasan Perdagangan dan Jasa, Jalan Kukusan Raya dan Jalan Tanah Baru berada pada Kawasan Permukiman. Dalam RTRW Kota Depok Tahun 2012 - 2032 Kawasan Margonda merupakan pusat perdagangan dan jasa, dimana Margonda ini berfungsi sebagai kawasan pusat pelayanan kota sebagai pusat pelayanan primer yang melayani seluruh wilayah kota dan/atau regional (Pemerintah Kota Depok, 2015). Jalan Raya Margonda merupakan akses menuju stasiun kereta api dan juga merupakan jalan terusan dari dan menuju pusat pemerintahan Kota Depok, sedangkan Jalan Kukusan Raya dan Jalan Tanah Baru akses jalannya tidak langsung menghubungkan dengan pusat pemerintah Kota Depok.

Fokus penanganan masalah infrastruktur di Kota Depok sebagaimana yang tercantum dalam RTRW Kota Depok 2012-2032 pada Pasal 21 ayat 1 yaitu peningkatan akses melalui pembangunan jalan baru; peningkatan kapasitas jalan yang telah ada; peningkatan kinerja simpang jalan tidak sebidang; dan penyediaan jalur khusus kendaraan tidak bermotor. Peningkatan kapasitas jalan yang telah ada sebagaimana dijelaskan lebih lanjut dalam bagian Penjelasan RTRW Kota Depok yaitu dalam bentuk pelebaran jalan. Dari ke empat puluh ruas jalan yang direncanakan akan dilakukan peningkatan kapasitas, dua diantaranya terdapat ruas Jalan Tanah Baru dan Jalan Kukusan Raya. Fokus penanganan pada ruas Jalan Raya Margonda yaitu penataan dan pengembangan sistem transportasi perkotaan yang berbasis pada terminal, halte, angkutan jalan, parkir, fasilitas pejalan kaki dan pelayanan kereta api.

\section{Kota Administrasi Jakarta Selatan}

Kecamatan Jagakarsa di Kota Administrasi Jakarta Selatan adalah kecamatan yang berada di paling selatan Provinsi DKI Jakarta, arahan perencanaan kecamatan dalam dokumen RTRW Provinsi DKI Jakarta 2030 sebagai kawasan peruntukan hijau budidaya dan kawasan peruntukan permukiman taman (permukiman kepadatan rendah dengan batas ketinggian bangunan adalah tiga lantai). Jika dirinci per ruas jalan, maka dapat diketahui bahwa ruas Jalan Lenteng Agung Raya, Jalan Srengseng Sawah, Jalan Moh. Kahfi I dan Jalan Moh. Kahfi II berdasarkan pola ruang dalam RTRW Jakarta 2030 masuk dalam Kawasan Permukiman. Dilhat dari struktur ruangnya, Jalan Lenteng Agung Raya merupakan jalan utama yang terhubung dengan Pusat Kegiatan Tersier Kawasan Pasar Minggu, jalan untuk menuju jalur tol JORR Selatan dan jalan yang terhubung untuk menuju 
pusat-pusat kawasan perkantoran seperti TB. Simatupang, sedangkan ketiga ruas jalan lainnya bukan merupakan ruas jalan yang menghubungkan langsung ke pusat kegiatan.

Empat ruas jalan yang di kaji dalam penelitian ini yaitu ruas Jalan Lenteng Agung Raya dan Jalan Srengseng Sawah di Kelurahan Srengseng Sawah, Jalan Moh. Kahfi II di perbatasan Kelurahan Srengseng Sawah dan Kelurahan Cipedak serta ruas Jalan Moh. Kahfi I di Kelurahan Cipedak, di dalam dokumen RDTR Provinsi DKI Jakarta termasuk ruas jalan yang direncanakan untuk dilakukan pemeliharaan jalan. Pemeliharaan jalan yang dimaksud dalam dokumen tersebut yaitu proses peningkatan kualitas jalan melalui penambahan material jalan dan perbaikan jalan guna memperbaiki kondisi jalan akibat penggunaan jalan setiap hari (Pemerintah Provinsi DKI Jakarta, 2014).

\section{Prioritas Penanganan Jalan}

Perbedaan kualitas jalan di perbatasan akan sangat terlihat jelas secara visual di lapangan. Penanganan ruas jalan tersebut masih bergantung kepada kebijakan masingmasing pemerintah daerah yang merupakan implikasi dari ketersediaan anggaran, sehingga terlihat bahwa penanganan jalan di daerah perbatasan masih bersifat parsial. Sebagai objek vital pergerakan manusia yang tentunya akan berdampak pada pergerakan barang/jasa maupun peningkatan ekonomi, sudah seharusnya ada kerjasama atau satu pemahaman antar pemangku kebijakan. Ujung dari semua itu adalah dapat memberikan pelayanan terbaik untuk masyarakat.

Arahan prioritas penanganan jalan di perbatasan Kota Depok dengan Kota Administrasi Jakarta Selatan disusun berdasarkan hasil sintesis dari tujuan penelitian sebelumnya. Kriteria yang digunakan dalam penyusunan prioritas merupakan gabungan dari unsur-unsur yang mendukung kelancaran manusia melakukan pergerakan/mobiltas. Dengan menggunakan parameter dan kriteria yang telah ditetapkan dan berdasarkan pendekatan dari hasil analisis sebelumnya, maka ditentukan ruas jalan yang menjadi prioritas penanganan yang dibedakan berdasarkan administrasi daerah penelitian. Hasil analisis disajikan pada Gambar 6.

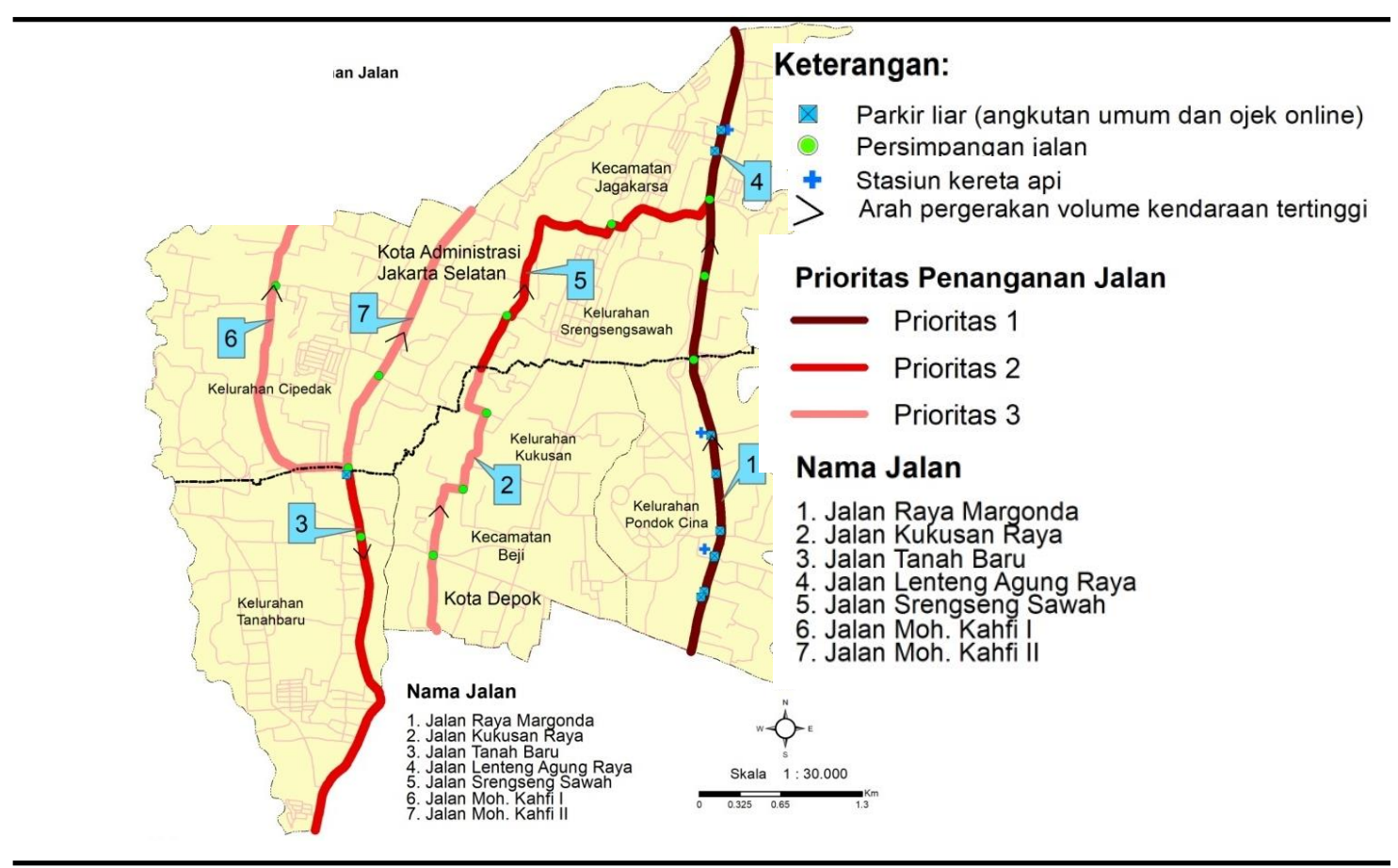

Gambar 6. Prioritas Penanganan Jalan 
Ruas jalan yang menjadi prioritas penanganan untuk meningkatkan kualitas jalan di perbatasan Kota Depok dengan Kota Administrasi Jakarta Selatan, yaitu: (1) ruas jalan perbatasan di Kota Depok, prioritas 1 yaitu Jalan Raya Margonda, prioritas 2 yaitu Jalan Tanah Baru, prioritas 3 yaitu Jalan Kukusan Raya; (2) ruas jalan perbatasan di Kota Administrasi Jakarta Selatan, prioritas 1 yaitu Jalan Lenteng Agung Raya, prioritas 2 yaitu Jalan Srengseng Sawah, prioritas 3 yaitu Jalan Moh. Kahfi I dan Jalan Moh. Kahfi II.

Penentuan arahan prioritas yang berdasarkan pada kondisi jalan beserta atributnya serta pelibatan masyarakat dalam memberikan penilaian kepuasan yang mereka rasakan sebagai pengguna manfaat dikaitan pula dengan dokumen rencana tata ruang wilayah yang dilakukan dalam penelitian ini dapat menjadi salah satu alternatif pendekatan dalam menentukan prioritas penanganan jalan terkait dengan daya dukungnya. Menggunakan pendekatan yang berbeda dari yang telah dilakukan oleh Miri (2014) dan Kartikasari (2017), karena penanganan jalan tidak hanya mengenai konstruksi jalan akan tetapi dapat pula berupa diberlakukannya rekayasa lalulintas guna mengatasi masalah yang terkait dengan daya dukung jalan.

Jenis penanganan yang dilakukan hendaknya atas dasar kerjasama kedua pemerintah daerah dengan memperhatikan kondisi jalan tersebut baik kondisi fisik, kondisi lingkungan maupun daya dukungnya, sehingga terjadi satu pemahaman dalam memberikan fasilitas pelayanan prasarana jalan yang terbaik di perbatasan bagi masyarakat. Diharapkan dengan dilaksanakannya penanganan jalan sesuai dengan prioritasnya akan memperlancar pergerakan/mobilitas masuk keluar manusia, barang maupun jasa. Kelancaran pergerakan/mobilitas tersebut akan berdampak pada peningkatan pertumbuhan ekonomi wilayah (Miri, 2014). Kota Depok sebagai kota penyangga DKI Jakarta akan berperan maksimal jika didukung oleh prasarana infrastruktur jalan yang baik.

\section{KESIMPULAN}

Kondisi jalan di perbatasan yaitu kondisi rusak ringan pada 2 jalan di Kota Depok dan 1 ruas jalan di Kota Administrasi Jakarta Selatan, kondisi sedang pada 1 ruas jalan di Kota Depok dan 3 ruas jalan di Kota Administrasi Jakarta Selatan. Kondisi perlengkapan jalan dan fasilitas pendukung di Kota Administrasi Jakarta Selatan dengan rata-rata 96\% lebih baik dibandingkan dengan pada ruas jalan di Kota Depok dengan rata-rata $86 \%$. Tingkat kepuasan masyarakat dalam kategori kurang puas ada pada dua ruas jalan di Kota Depok, sedangkan keseluruhan jalan di Kota Administrasi Jakarta Selatan dalam kategori cukup puas. Daya dukung untuk ke tujuh ruas jalan yang diteliti berada dalam kategori cukup baik hingga sangat buruk, dimana daya dukung jalan sangat buruk berada di Jalan Tanah Baru Kota Depok. Secara keseluruhan daya dukung jalan yang ada di Kota Administrasi Jakarta Selatan lebih baik dibandingkan dengan daya dukung jalan yang ada di Kota Depok.

Berdasarkan hal tersebut, maka arahan prioritas penanganan jalan untuk peningkatan kualitas jalan yaitu: a) Kota Depok, prioritas 1 Jalan Raya Margonda dan prioritas 2 Jalan Tanah Baru, prioritas 3 Jalan Kukusan Raya; b) Kota Administrasi Jakarta Selatan, prioritas 1 Jalan Lenteng Agung Raya, prioritas 2 Jalan Srengseng Sawah dan prioritas 3 Jalan Moh. Kahfi I serta Jalan Moh. Kahfi II.

\section{DAFTAR PUSTAKA}

Aziza, T. N. (2017). Evaluasi Standar Pelayanan Minimal (SPM) Pekerjaan Umum dan Penataan Ruang Kota Samarinda: Sebuah Upaya Menuju Perbaikan. Jurnal Borneo Administrator, 12(3), 259-277. https://doi.org/10.24258/jba.v12i3.254

Chengula, D. (2018). Study on Performance of Road Signs and Markings along TANZAM Highway in International Journal of Sciences: Study on Performance of Road Signs and Markings along TANZAM 
Highway in Mbeya Region , Tanzania Duwa Hamisi Chengula *. International Journal of Sciences: Basic and Applied Research (IJSBAR), 39(1), 34-50.

Departemen Pekerjaan Umum RI. (1997). Manual Kapasitas Jalan Indonesia (Vol. 1). https://doi.org/10.1021/acsami.7b07816

Hadijah, I, Putra, D. (2017). Analisa kerusakan perkerasan jalan ditinjau dari daya dukung tanah dan volume lalu lintas (Studi Kasus : Ruas Jalan Metro - Tanjung Kari di Kecamatan Sekampung Lampung Timur STA $10+600 \mathrm{~s} / \mathrm{d}$ 11+600). Tapak, 71), 64-69.

Irawan, H., Ismiyati, I., \& Pudjianto, B. (2016). Penentuan skala prioritas penanganan jalan kabupaten di kabupaten kudus dengan metode analytical hierarchy process. Teknik, 372), 72-77. https://doi.org/10.14710/teknik.v37n2.8411

Pemerintah Provinsi DKI Jakarta. (2012). Rencana Tata Ruang Wilayah Provinsi 2030.

Kartikasari, D. (2017). Analisis jaringan jalan dan arahan prioritas penanganannya di kabupaten purworejo, provinsi jawa tengah dewi kartikasari.

Kentjana, N. H., Wibowo, A., \& Nurlambang, T. (2016). Pemetaan Pergerakan Lalu Lintas Kendaraan Di Kelurahan Kukusan Kota Depok. Majalah Ilmiah Globe, 18(2), 61. https://doi.org/10.24895/MIG.2016.18-2.386

Mathew, T. V, \& Rao, K. (2007). CHAPTER 35. CAPACITY AND LEVEL OF SERVICE NPTEL Capacity and Level of $\quad$ service $35.1 \quad$ Overview. https://nptel.ac.in/courses/105101087/downloads/Lec-35.pdf

Miri, G., Barus, B., \& Soma, S. (2014). Analisis Perencanaan Priortas Jaringan Jalan untuk Pengembangan Wilayah di Kabupaten Tana Toraja. Jurnal Tanah Lingkungan, 16(1), 1-8.

Muanisah S, E. (2014). Koordinasi Pengaturan Rambu-Rambu Lalu Lintas di Kabupaten Siak. Jom FISIP, 1(2), $1-10$.

Palin, A., Rumayar, A. L. E., Lintong, E., Teknik, F., Teknik, J., Universitas, S., \& Ratulangi, S. (2013). Analisa kapasitas dan tingkat pelayanan pada ruas jalan wolter monginsidi kota manado. Jurnal Sipil Statik, 1(9), 623-629.

Pemerintah Kota Depok. (2015). PERDA RTRW-Rev01_27Agustus15.

Pratama, T. A., Rahman, T., \& Rahman, N. (2011). A k k f b k s. Prosiding Seminar Nasional Penelitian Dan PKM Sains, Teknologi Dan Kesehatan, 311-318.

Siahaan, D. A., \& Surbakti, M. S. (2014). Analisis Perbandingan Nilai IRI Berdasarkan Variasi Rentang Pembacaan NAASRA. Proceeding The 17th FSTPT International Symposium; 22 - 24 Agustus 2014, (August), 22-24.

Sitanala, F. (2005). Pergerakan Penduduk Kota Depok Menuju ke Tempat Bekerja Tahun 2001. Makara Sains, 9(1), 41-44. 